\title{
Um eclipse e três estrelas da manhã: Duprey, Toyen e Breton unidos em Sacrilégio
}

\author{
An Eclipse and three morning stars: Duprey, Toyen and Breton united in Sacrilege
}

\author{
THIANE NUNES* \\ Universidade Federal do Rio Grande do Sul, Porto Alegre, RS, Brasil
}

\begin{abstract}
Resumo: Um encontro pode resultar em uma descoberta, e uma ocorrência arriscada. Assim iniciei meu contato mais pessoal na interação entre arte e literatura, e nesse mundo dos livros ilustrados, dos livros únicos e daqueles livros propensos a não serem apenas livros. Ofertado por um sol negro (a excêntrica editora Le Soleil Noir), sob a égide de um prefácio escrito por um artista surrealista (André Breton), La Forêt Sacrilège nos convida a levar em conta a experiência de uma confluência, no encontro de um poeta alérgico e silencioso (Jean-Pierre Duprey) e de uma artista alergênica e silenciada (Toyen, como ilustradora). La Forêt Sacrilège trata de um texto em prosa poética e narrado em cenas, imitando uma peça teatral, sem ter intenção de sê-la. A escrita traz consigo esse jogo perigoso: é um laboratório onde o que se nomeia não é a coisa em si e onde o poeta trabalha as palavras e as palavras trabalham o poeta.
\end{abstract}

Palavras-chave: livro de artistas; poesia surrealista; livros colaborativos.

\begin{abstract}
A meeting can result in a discovery, and a risky occurrence. Thus I began my most personal contact in the interaction between art and literature, and in this world of picture books, unique books and those books prone to not be just books. Offered by a black sun (the eccentric publisher Le Soleil Noir), under the aegis of a preface written by a surrealist artist (André Breton), La Forêt Sacrilège invites us to take into account the experience of a confluence in the encounter of a silent allergic poet (Jean-Pierre Duprey) and a silenced and allergenic artist (Toyen, as an illustrator). La Forêt Sacrilège deals with a text in poetic prose and narrated in scenes, imitating a theatrical play, without intending to be one. Writing carries with it this dangerous game: it is a laboratory where what is named is not the thing itself and where the poet works the words and words work the poet.
\end{abstract}

Keywords: book of artists; surrealistic poetry; collaborative books. * Doutoranda em Artes Visuais, com ênfase em História, Teoria e Critica pelo Programa de Pós-Graduação da Universidade
Federal do Rio Grande do Sul. <thianenunes@gmail.com>> 
Para Michael Löwy, o surrealismo, muito mais do que uma escola literária ou um grupo de artistas, foi um movimento de revolta do espírito e tentativas de reencantamento do mundo. Em seu livro, A Estrela da Manhã, Surrealismo e Marxismo, ele nos diz que essa afluência "nunca deixou de ser um lugar mágico de resistência, uma transparente luz de recusa, um espírito irônico de negação de todas essas viscosas manifestações de sujeição mitológica" (Löwy, 2002, p. 28). Entretanto, é sabido que sob a fraca e luciferiana luz da manhã alguns espíritos se dobram, e algumas estrelas se quebram.

Um encontro pode resultar em uma descoberta, e uma ocorrência arriscada. Assim iniciei meu contato mais pessoal na interação entre arte e literatura, e nesse mundo dos livros ilustrados, dos livros únicos e daqueles livros propensos a não serem apenas livros. Sob a égide de um prefácio ofertado por um sol negro, um escritor surrealista (André Breton) nos convida a levar em conta a experiência de uma confluência, no encontro de um poeta alérgico e silencioso (Jean-Pierre Duprey) e de uma artista alergênica e silenciada (Toyen). Ou tudo isso completamente ao contrário. La Forêt Sacrilège (1970) trata de um texto em prosa poética e narrado em cenas, imitando uma peça teatral, sem ter intenção de sê-la. A escrita traz consigo esse jogo perigoso: é um laboratório onde o que se nomeia não é a coisa em si e onde o poeta trabalha as palavras e as palavras trabalham o poeta.

Escrito por Jean-Pierre Duprey, após um período de silêncios a qual se dedicou à escultura, o texto principal desta obra abrange os prováveis anos de 1953 a 1959, época em que também esteve preso e sofreu internação manicomial. Evocam a sombria lucidez de quem assiste sua própria impotência indo de encontro ao vácuo, em alusões proféticas e humor tensionado, onde o sacrilégio e a profanação do sagrado tornam-se palco e cenário. Duprey viria a cometer suicídio em seu estúdio, em outubro de 1959, logo após o envio de seus últimos manuscritos para o amigo André Breton. Tinha 29 anos.

La Forêt Sacrilège et autres textes foi publicado pela Le Soleil Noir, como terceira e última parte de uma trilogia das obras do autor, no ano de 1970, onze anos após sua morte. Fundada e editada em Paris por François Di Dio e Nicole Ménant, a editora publicou mais de 150 livros de poesia, arte, livros-objeto, literatura e traduções do hinduísmo e do sânscrito, entre 1950 e 1983. O humor negro, indo além da ironia e do chiste, assim como a exaltação noir, tem uma grande ressonância no surrealismo, especialmente no período após a Segunda Guerra Mundial, o que fica visível na produção de uma constelação de poetas da chamada geração negra ${ }^{1}$, incluindo Jean-Pierre Duprey e Stanislas Rodanski. A editora Le Soleil Noir, que empresta seu nome de uma citação de escritos do escritor e ocultista francês do século XIX, Eliphas Levi², como ilustrado na contracapa de suas publicações (Fig. 1), publicou as obras completas desses dois poetas, que também experimentaram os horrores da guerra pessoalmente.

\footnotetext{
Em RÉQUICHOT, Bernard. Les Écrits, 1973. O prefácio é assinado por Alain Jouffroy, que em seu texto Lettre Noire utiliza a expressão "génération noire" ou "société secrèt de l'ecriture".

2 Do livro A Chave dos Grandes Mistérios. "Le téméraire qui ose regarder le soleil sans ombre devient aveugle at alors pour lui le soleil est noir": $O$ imprudente que se atreve a olhar para o sol sem proteção torna-se cego, então, para ele, o sol é negro (tradução da autora).
} 


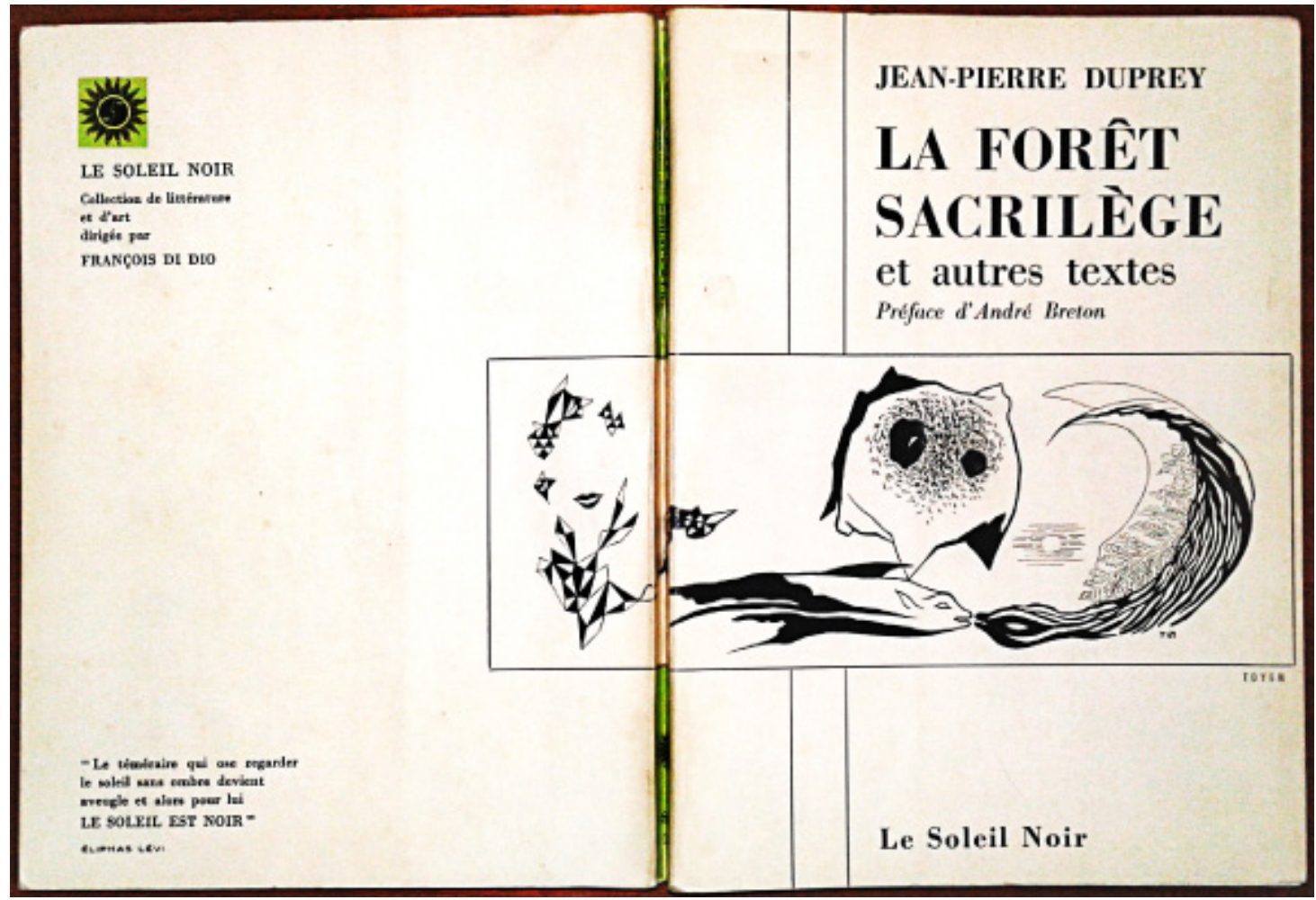

Figura 1. DUPREY, Jean-Pierre. La Forêt Sacrilège et autres texts. Paris: Le Soleil Noir, 1970. (Fotografia e exemplar: acervo da autora.)

Durante a ocupação em 1944, Rodanski, então com dezessete anos de idade, foi deportado para Mannheim, preso em um campo de trabalho. Após o terrível bombardeamento de Rouen, em 19 de abril de 1944, Duprey (que tinha apenas quatorze anos) participa, com os outros estudantes de uma classe, em operações de "limpeza". Ele chega a escrever em seus cadernos que estava exausto e em pedaços, por ter passado dias "enterrando corpos e pedaços de morte" (DI DIO, 1990, p. 86). Para a geração surrealista de Breton, Louis Aragon e Benjamin Péret, a Grande Guerra foi uma verificação absurda da espantosa estupidez dos valores da sociedade; Para os adolescentes da "geração negra", o conflito foi pessoalmente físico e perturbador, talvez ainda mais pernicioso.
O exemplar numerado pelos algarismos 1868 (Fig. 2) é prefaciado por André Breton e ilustrado com seis desenhos da artista tcheca Toyen. A aproximação do texto de Duprey com as imagens encomendadas para a artista, feitas para o livro, teria sido um projeto do próprio Breton, levando-se por seus afetos. Compreender e tentar desvendar absolutamente do que se trata toda essa convergência de relações intertextuais, transformada em um livro, não é tarefa leviana. Tentarei esboçar uma abordagem crítica sobre esse objeto que reviro e toco com as mãos, mas que me toca de outra forma, que não me deixa indiferente por todo seu contexto e construção.

As seis ilustrações, em papel distinto do texto, encontram-se ao final dessa edição, 
Ce livre, qui constitue l'édition originale de «La Forêt Sacrilège et autres textes » a été tiré à deux mille sept cent quarante neuf exemplaires se répartissant en :

quatre - vingt - dix - neuf exemplaires sur vélin d'Arches avec, en hors texte, six pointes sèches de Toyen, tirées sur soie par l'imprimerie Lacourière-Frelaut. Ces exemplaires, numérotés de 1 à 99 , sont inclus dans une sculpture de Toyen moulée en polystyrène expansé, présentée sous un emboitage transparent construit par l'atelier Jean Duval;

trois cents exemplaires sur offset Sirène, dans la série « club » du Soleil noir, sous emboítage transparent contenant la sculpture de Toyen, signés et numérotés de $\mathrm{C} 1$ à C 300 ;

deux mille trois cent cinquante exemplaires sur offset Sirène numérotés de 301 à 2650 .

\section{EXEMPLAIRE}

$$
1000
$$

Figura 2. DUPREY, Jean-Pierre. La Forêt Sacrilège et autres texts.

(Página 9 desse exemplar. Fotografia: acervo da autora.)

a mais simples de uma tiragem feita em três partes e com diferentes apresentações. São todas em um fundo verde (Fig. 3). Na versão mais cara, são apresentadas em gravuras em metal, na mesma coloração. Observo uma duplicação do mesmo texto inicial de Breton, ao final do livro. Esse duplo prefácio parece fazer parte de todas as edições, mantendo o texto principal preso entre ambos. As questões do pensamento duplo e do aprisionamento entre as duplicidades de sua própria presença como ser foram importantes no trabalho de Duprey. Em 1950, ele havia escrito Derrière son double, muito elogiado por Breton, que naquele ano o incluiria na segunda edição

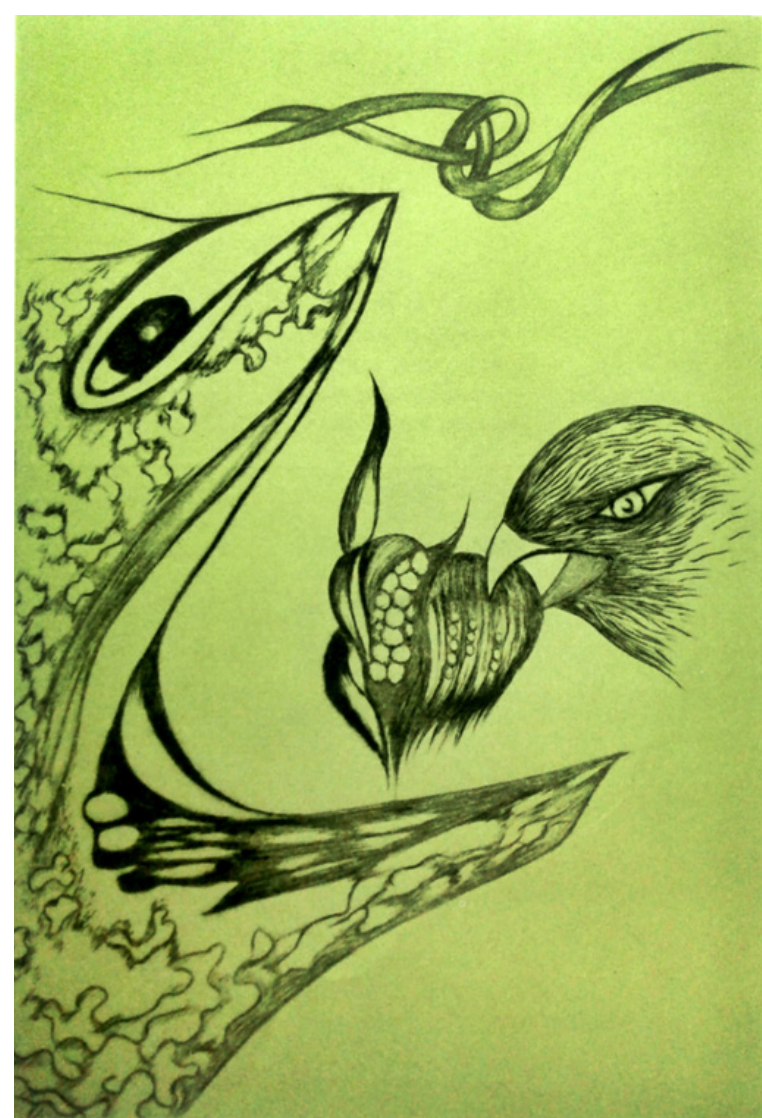

Figura 3 - Toyen. La Forêt Sacrilège et autres texts. Ilustração para o livro.

(Página não numerada desse exemplar. Fotografia: acervo da autora.)

de seu Anthologie de l'humor noir. Além disso, seu amigo Jacques Brenner havia Ihe apresentado Artaud, autor de $O$ Teatro e Seu Duplo, a quem admirava. No anseio de fazer parte do jogo, o leitor pode correr o risco de pensar um possível erro de editoração como outra coisa, conspirando para um novo entendimento e fantasia, entre a arte e os sintomas surrealistas.

Duprey parece enxergar algo terrivelmente difícil e que caminha em direção a um tipo de finitude como salvação. As incertezas povoam o seu texto. Ele se faz muitas perguntas, e nos mobiliza a nos questionar igualmente, numa realidade psíquica distorcida ou mista: Eu sou um homem? Eu 
sou uma mulher? Estou vivo ou morto? A letra no inconsciente reflete a repressão, a do gozo do corpo, que sempre acaba por fazer valer os seus direitos. Escrevendo o sonho, usa a metáfora. São textos estranhos, que oscilam entre ligação e desligamento, impulsionam-se num fluxo contínuo que o poeta produz e expele, voraz, extraindo de si. A letra fala, pela lei da repetição, numa busca frenética por certo alívio, ao dar palavra para as coisas sentidas.

Fazendo a ponte entre o que se escreve e a desordem do mundo, a aventura surreal de Duprey procura atravessar paredes e permite uma regressão, uma descida em si mesmo. Seu sacrifício poético funciona como uma prática para o abismo. Testemunhando a dor de existir, essa produção traz consigo esse destino perigoso: paga-se muito caro por essa descida, onde o corpo é uma concha vazia e as palavras funcionam como fagulhas sob a pele. Neste trabalho terrível e, finalmente, ilustrado como sonho, não há lugar para uma fantasia lúdica e inofensiva.

Assim dito, devemos lembrar que a leitura de poesia pode ser um exercício incerto: algumas leituras não nos dão trégua e nos assombram; acrescidas de determinadas imagens, nada autônomas, não nos deixam incólumes. Se por um lado Duprey nos leva desde as primeiras palavras para um universo quente e alucinatório, aquele lugar que reside entre a respiração e a expiração, por outro Toyen ilustra as palavras com visões rabiscadas num fundo verde de charco, onde algo sempre engole ou absorve algo. As seis ilustrações para La Forêt Sacrilege enfatizam uma espécie de acoplamento. Eros e Thanatos, nossas porções de vida e morte, o que existe e logo mais não existirá.
Aussi tu dois mourir deux fois - mais à cela les poisons ne peuvent rien et la troisième seule sera la bonne. Et maintenant adieu! Je te retrouverai entier à la pointe du feu, après ta dernière vie... (DUPREY, 1970, p. 40). ${ }^{3}$

A verdade é que devo a Toyen a descoberta da poética de Duprey. Foi na pesquisa dessa figura feminina e miticamente obscura do início do século $X X$, que negociava papéis de gênero não conformistas e marginalizados dentro de importantes circuitos da vanguarda artística dominado por homens ${ }^{4}$, e investigando sua atuação em relação à ilustração literária ${ }^{5}$ que cheguei a ele, um dos mais marginais dos surreais, nas palavras do escritor e crítico literário Jean-Pierre Vallotton, que o incluiria de forma afetiva a outros artistas periféricos como Vaché, Cravan e Unica Zürn.

Toyen ainda era bastante jovem quando iniciou sua produção em arte nos primeiros anos da década de 1920. Sua grande discrição e sua recusa de qualquer forma de compromisso impediram durante muito tempo que Toyen ocupasse o lugar que era dela na constelação de pintores surrealistas. Seu trabalho mais tardio, como as ilustrações feitas para esse livro - embora com teor menos explícito do que o erótico inicial com a qual é seguidamente relacionada -, desenvolve um vocabulário evasivo, mas intensamente

\footnotetext{
3 Então você tem que morrer duas vezes - mas os venenos não irão ajudá-lo - e na terceira vez será agradável. E agora adeus! Eu os encontrarei todo na vanguarda da vida, após uma derradeira e última vida (tradução da autora). 4 Como o Devětsil e os grupos surrealistas de Praga e Paris.

5 Ilustrou publicações e revistas como Lotos, Olisbos, Mys dobré naděje e Edice 69, além de projetos como Vênus de Beardsley e Tannhäuser (1930), Josephine Mutzenbacher de Salten: Memoirs of a Vientians Tart (1930) e Pybrac de Louÿs (1932), bem como Heptameron (1932), Lady Chatterley's Lover (1930) e Justine, de Sade (1932). Ilustra poemas e livros de Breton, Peret, Octavio Paz e recémchegados ao movimento surrealista francês, como Gérard Legrand, Elie-Charles Fleming, Radovan Ivsic e Annie Lebrun.
} 
sensual em relação ao estranho, aos estados intermediários e duplos, como as questões dos papéis de gênero e a androginia, o outono, a madrugada, o crepúsculo, a memória, a morte e o sonho, a natureza e o esvaziamento, temas e significantes recorrentes em sua produção.

Nos primeiros cinco anos da sua carreira, Maria Cerminova era como a artista assinava os seus trabalhos, seu nome de nascimento, da qual pouco se sabe, já que havia rompido relações familiares muito cedo e recusava-se a falar sobre sua vida particular. O pseudônimo Toyen passou a ser usado a partir de 1923, sendo a abreviatura da palavra citoyen, que significa cidadão, e no francês se refere a ambos os sexos. Tanto um membro fundador do grupo surrealista de Praga como um membro do grupo surrealista pós-guerra de Paris, ela não só adotou um pseudônimo desprovido de gênero, como enfatizava sua rejeição da fala e escrita heteronormativa, jogando com as palavras, com seus discursos e vestindose conforme os modelos masculino e feminino da época, estratégias entendidas como de sobrevivência e visibilidade num ambiente sabidamente misógino, alérgico a feminismos.

Toyen diferiu da maioria de suas Colegas mulheres em relação aos temas eróticos e na representação da sexualidade. A arte das mulheres dificilmente era uma imagem espelhada dos homens, que tendia a erotizar e sexualizar o corpo feminino, de acordo com uma visão androcêntrica de mundo. Nesse sentido, a imagem fálica e a representação do masculino de Toyen é talvez o único trabalho de uma mulher artista de sua geração que usa o corpo do sexo oposto para explorar a sexualidade de uma maneira semelhante à do uso masculino do corpo feminino.
Com o passar do tempo, Toyen começa a explorar o erotismo de forma mais velada e simbólica, enfatizando o vazio, a fragmentação e a sensação de horror fantasmático. Essas obras não são eróticas no sentido usual da palavra, mas irradiam uma aura de angústia e dor, muitas vezes focada no corpo feminino. Percebe-se o desenvolvimento da imagem de uma mulher solitária, geralmente pré-púbera, que vaga perdida por paisagens sombrias, entre as justaposições perturbadoras de brinquedos e animais mortos, por vezes fragmentada e desmembrada. Nenhuma das ilustrações para Justine (1932), por exemplo, mostra uma figura completa: as composições mostram torsos, genitais e rostos. Em Message of the Forest (1936, Fig. 4) observamos a cabeça decapitada de uma menina. Em Prometheus (1934) e The Abandoned Corset (1937), o conteúdo sexual da peça é frequentemente sugerido e não explícito. Como Whitney Chadwick observa: "Eles parecem se intrometer no mundo natural como significantes de formas ameaçadoras que estão presentes e ausentes. A tensão ansiosa entre o que é completo e o que não é, entre o visível e o invisível" (CHADWICK, 1998, p. 73).

Após a visita de Breton e Eluard a Praga em 1935, Styrsky, Toyen e seus amigos Nezval e Teige participaram de publicações surrealistas e exposições internacionais. Durante a ocupação nazista, Toyen está na lista de intelectuais a quem qualquer manifestação pública é proibida. Após o stalinismo governar seu país, ficaria mais difícil trabalhar livremente, e, em 1947, não vê outra escolha senão o exílio em Paris. Até a dissolução do grupo em 1969, ela se associa completamente a todas as suas atividades, incluindo a política. Ilustra as revistas, poemas e livros de Breton, 


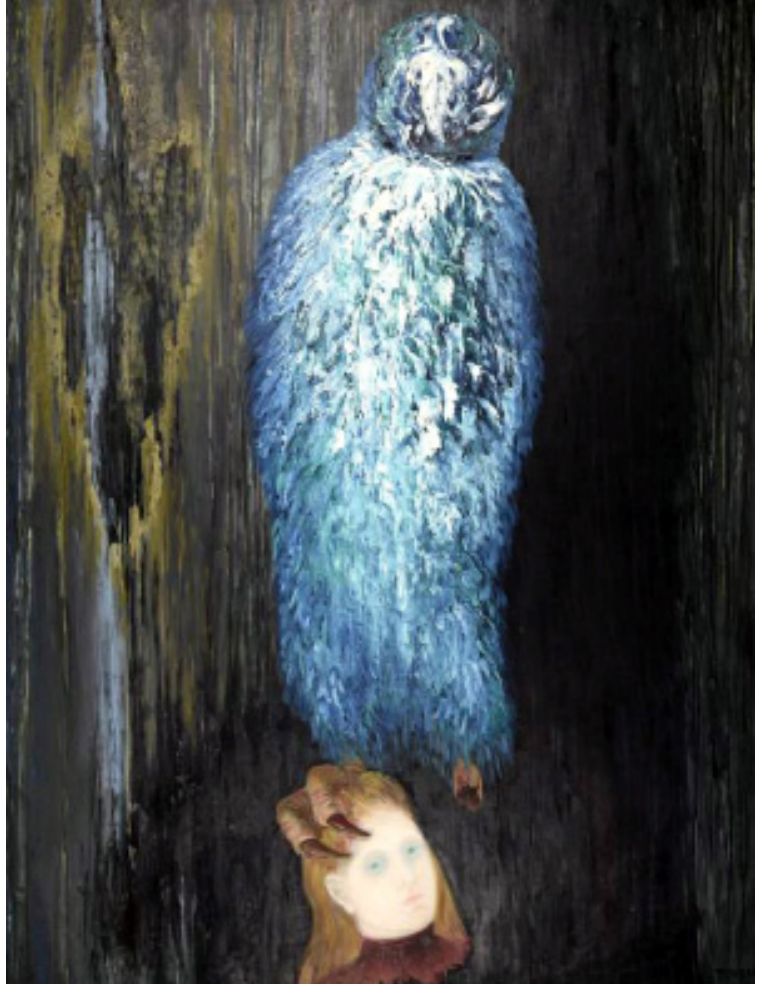

Figura 4. Toyen, Poselstvi Lesa (Message of the Forest), 1936. National Galleries Scotland.

(Fonte: <https://www.nationalgalleries.org/art-and-artists/156267/ message-forest-poselstvi-lesa>.)

Péret (que chamava carinhosamente de "baronesa"), Octavio Paz e dos jovens Gérard Legrand, Élie-Charles Flamand, Jean-Pierre Duprey, Radovan Ivsic e Annie Lebrun.

No final da Segunda Guerra Mundial, a arte de Toyen alcançou plena maturidade. Natureza, animais e pássaros passam a expressar sua produção a partir da década de 1950. As imagens de acasalamento de insetos são frequentes, como nos besouros de So Far, So Old (1955) e nas borboletas em Paravent (1966). Gatos selvagens, cães, lagartos e rãs, aves, peixes e antropomorfismo indicam questões relativas ao feminino, sugerindo a presença por uma espécie de ausência. Suas obras eróticas de surrealismo são mais veladas e misteriosas do que as de Styrsky e outros surrealistas homens.
É difícil encontrar algum registro de como se deu o encontro em vida desses dois personagens, Toyen artista e Duprey poeta. Este último iria se unir ao movimento surrealista tardio, da segunda metade do século XX, por breve período. Poeta, pintor e escultor, Jean-Pierre Duprey, nascido em 01 janeiro de 1930, em Rouen, viveu uma infância difícil, marcada por desequilíbrios psíquicos e repetidas crises anoréxicas, fato incomum ao seu gênero, além de pouco entendido à época. Não suporta o rigor escolar, sendo expulso da escola ainda bem jovem. Aos quatorze anos escreve seus primeiros poemas, publicados em revistas de poesia e arte marginais e de subcultura. Descobre Lautréamont, Jarry e Artaud. No verão de 1948 conhece Jacqueline Senart, e assim como Toyen, rompe com sua família e se muda para Paris. Duprey termina de escrever Derrière son double, seu primeiro manuscrito, e envia por correio para André Breton. Este último the responde com empolgação em 18 de janeiro de 1949. Foi assim que ele encontrou o resto do grupo surrealista disperso pela guerra. Duprey escreve muito e silenciosamente se mistura com as reuniões artísticas e políticas do movimento, antes de recuar para um momento de profundo silêncio das palavras, a partir de 1951, onde a poesia é abandonada temporariamente em favor da pintura e da escultura em ferro. Neste momento, ele parece estar procurando por algo além, quando a linguagem da escrita parece não ser suficiente.

Em seus textos, tanto em verso como em prosa, no formato lírico, narrativo ou na forma de diálogos, a poesia de Jean-Pierre Duprey não me lembra de qualquer outra que já li. Mas me invade com muitas imagens próprias do movimento artístico a que fazia parte, território eleito do mito, da angústia, 
do sonho maravilhoso ou fantástico. Penso nas beiradas dos precipícios e nos fundos dos poços por onde flui a água negra que não reflete nada. Seu trabalho encarna uma alquimia notável e dolorosa ao mesmo tempo, personificando a dualidade dilacerante entre sonho e realidade.

Em 1959, após um período de privação social e sofrimento emocional e em protesto contra a guerra na Argélia, Duprey urina sobre o túmulo do Soldado Desconhecido, sob o Arco do Triunfo. Acaba preso e violentamente espancado. Depois de algum tempo na prisão, é internado no Hospital Sainte-Anne, em julho de 1959. O poeta Alain Jouffroy, que o visita, relata o testemunho:

Os gritos que chegam até seu quarto durante a noite em Sainte-Anne o impedem de dormir. Quando cheguei para visitá-lo no período da tarde, ele se levantou e ficou em pé, com um sorriso imóvel, ao lado de sua cama. EntregueiIhe os livros sobre vudu e magia, mas seus olhos pareciam vazios. Às minhas perguntas, ele respondia evasivamente por "talvez", ou "sim, é possível." E então de repente ele começou a rir, e por alguns segundos nos encontramos e ficamos cúmplice rindo, sem fala, sem frases. Ao matar o diálogo, ele preservou a aparência de vida. Além das palavras, tudo ficou maravilhosamente brilhante. (JOUFFROY apud KOLÁR̆, 1973, p. 88) ${ }^{6}$.

Em agosto do mesmo ano retorna para casa, e passa os seus últimos meses de vida escrevendo o que viria a ser seu último trabalho: $O$ fim e o caminho, onde expressa febrilmente poemas trágicos e de desespero profundo. Em 2 de outubro de 1959, depois de enviar por sua companheira seus últimos manuscritos para André Breton - da mesma

6 Correspondência pessoal entre os poetas Alain Jouffroy e Jiři Kolár̆. forma como havia feito dez anos antes com seus primeiros trabalhos -, o poeta termina seus dias, enforcado na viga principal do seu estúdio na Rue du Maine. Três dias antes ele teria dito a Jouffroy por telefone: "Eu sou alérgico a esse mundo".

No início do surrealismo, Jacques Rigaut, Jacques Vaché e Arthur Cravan, três suicídios da sociedade, fascinaram seus contemporâneos; Para alguns dos mais jovens, estrelas fugazes e rápidas a se extinguir, - como Duprey, Rodanski, Paalen e Requichot - o abismo os conduziu para outro lugar: além de todos os antiheróis, marginais das margens, não-artistas. Herdeiro do movimento surrealista, Duprey foi um verdadeiro poeta, para a qual a escrita era uma prática desse abismo. Um desertor da literatura, da arte e da vida.

\section{Referências}

BAILLY, Jean-Christophe. Jean-Pierre Duprey. Paris: Seghers, 1973.

CAWS, Mary Ann, et al. (Ed.). Surrealism and Women. Cambridge, MA: MIT Press, 1991.

CHADWICK, Whitney. The Muse as Artist: Women in the Surrealist Movement, in: Art in America, v. 73, n. 7, p. 120-129, July 1985.

CHADWICK, Whitney. Mirror Images: Women, Surrealism, and Self-Representation. Cambridge, MA: MIT Press, 1998

DI DIO, François. Biographie de J-P Duprey. In: Duprey. OEuvrés Completes. Paris: Christian Bourgeois, 1990.

DUPREY, Jean-Pierre. La Forêt Sacrilège et autres texts. Paris: Le Soleil Noir, 1970.

LÖWY, Michael. A estrela da Manhã. Surrealismo e Marxismo. Rio de Janeiro: Civilização Brasileira, 2002.

RÉQUICHOT, Bernard. Les Écrits. Bruxelles: La Connaissance, 1973.

SPECTOR, Jack J. Surrealist Art and Writing, 19191939. Cambridge: Cambridge University Press, 1997.

Recebido: 9 de julho de 2017.

Aceite: 10 de outubro de 2017 